\title{
Odor memory: Review and analysis
}

\author{
RACHEL S. HERZ \\ Monell Chemical Senses Center, Philadelphia, Pennsylvania \\ and \\ TRYGG ENGEN \\ Brown University, Providence, Rhode Island
}

\begin{abstract}
We critically review the cognitive literature on olfactory memory and identify the similarities and differences between odor memory and visual-verbal memory. We then analyze this literature using criteria from a multiple memory systems approach to determine whether olfactory memory can be considered to be a separate memory system. We conclude that olfactory memory has a variety of important distinguishing characteristics, but that more data are needed to confer this distinction. We suggest methods for the study of olfactory memory that should make a resolution on the separate memory system hypothesis possible while simultaneously advancing a synthetic understanding of olfaction and cognition.
\end{abstract}

Odor memory refers to both memory for odors and memory that is associated to or evoked by odors. Odor memory first came under psychological scrutiny at the beginning of this century (Bolger \& Tichener, 1907; Heywood \& Votriede, 1905; Kenneth, 1927; Laird, 1935). The earliest investigators compared verbal associations with odors and pictures as cues, with the finding that odors were generally inferior reminders (Bolger \& Tichener, 1907; Heywood \& Votriede, 1905). Later, Kenneth (1927) described the emotions and personal associations that various odors evoked, and Laird (1935) summarized the characteristics of odor-evoked memories as retrospectively reported by 254 "men and women of eminence." However, the topic of odor memory was not investigated with modern experimental methods until the early 1970 s, when Engen and his students began to investigate memory for odors by using paradigms modified and borrowed from the tradition of verbal learning. Over the past 20 years, cognitive experimentation on odor memory has slowly grown, and, in the last 10 years, major advances in understanding olfactory processing have been made using neurological techniques (Pelosi, 1994). The psychiatric benefits of odor during therapy have also been discussed (King, 1988).

Cognitive olfactory research has addressed a variety of factors, such as the role of verbal mediation in olfactory processing, the duration of olfactory memory, olfactory recall and imagery, implicit memory for odors, odor-evoked autobiographical memory, and odor-based context-dependent memory. Neuroscientific investiga-

The authors wish to thank Fergus Craik, Robert Crowder, Pamela Dalton, Eric Eich, Howard Eichenbaum, Robert Greene, Brian Lyman, Russ Mason, Mark McDaniel, Roddy Roediger, and Marilyn Smith for many helpful comments on earlier versions of this manuscript. Correspondence should be addressed to R. S. Herz, Monel] Chemical Senses Center, 3500 Market St., Philadelphia, PA 191043308 (e-mail: herz@pobox.upenn.edu). tions have primarily focused on comparisons of impaired versus spared dissociations in clinical populations.

Our review of odor memory will focus on the cognitive literature. Relevant neurophysiological research will be discussed where it supports and elucidates the cognitive data. The goal of this paper will be to summarize the extant research on odor memory, suggest a theoretical framework for conceptualizing odor memory, and point to new experimental directions that would most profitably further the field. By way of introduction to the topic of olfactory memory, we begin with a brief description of the distinguishing neurobiological and neuroanatomical characteristics of olfaction.

The primary olfactory cortex forms a direct anatomical link with the amygdala-hippocampal complex of the limbic system. Only two synapses separate the olfactory nerve from the amygdala, which is critical for the expression and experience of emotion (Aggleton \& Mishkin, 1986) and human emotional memory (Cahill, Babinsky, Markowitsch, \& McGaugh, 1995). Only three synapses separate the olfactory nerve from the hippocampus, involved in the selection and transmission of information in working memory, short- and long-term memory transfer, and various declarative memory functions (Eichenbaum, in press; Schwerdtfeger, Buhl, \& Gemroth, 1990; Staubli, Ivy, \& Lynch, 1984, 1986). No other sensory system makes this kind of direct and intense contact with the neural substrates of emotion and memory, which may explain why odor-evoked memories are unusually emotionally potent (see Autobiographical OdorEvoked Memory section, below). Moreover, in all other sensory modalities, limbic projections are made after a series of cortical relays through higher order associational areas (Insausti, Amaral, \& Cowan, 1987; Turner, Mishkin, \& Knapp, 1980).

Another unique feature of olfaction is that sensory information is routed from the olfactory bulb to cortical re- 
gions of the brain without a thalamic relay (where sensory integration and transfer take place; Farbman, 1992). Indeed, there is evidence that basic-level olfactory processing, such as odor detection, discrimination, and simple odor retention, occurs in the primary olfactory cortex and not at higher cortical levels (see Carmichael, Clugnet, \& Price, 1994, for a review). In all other sensory systems, incoming information is processed in the thalamus before it is projected to the cerebral cortex.

Neural transduction in the olfactory system is also characterized by several singular and primitive features. For one, olfactory neurons are unmyelinated. They are among the smallest in the body and possess the slowest conducting velocities. Presumably, these factors underlie the fact that olfaction is our slowest sense. In vision, detection takes about $45 \mathrm{msec}$ (Robinson, 1968), whereas olfactory detection takes close to $400 \mathrm{msec}$ (T. Radil, personal communication, March 14, 1995) and recognition takes $600-800 \mathrm{msec}$ (Laing \& MacLeod, 1992). Once perceived, the sensation of an odor also persists for greater lengths of time than do sensations produced by the other senses. An odor cannot be experienced in a flash analogous to a flash of light (Levine \& McBurney, 1986). This is not surprising given that odors diffuse through air gradually. Furthermore, human olfactory sensitivity is not spatially specific. That is, unlike our senses of vision or hearing, we cannot localize precise spatial coordinates for olfactory sources in the absence of other physical cues.

Olfactory receptors are the only CNS neurons directly exposed to the environment, and they are also unique in that they are the only neurons known to regenerate, with complete replacement of receptors approximately every 28 days. This has obvious biological significance given the direct exposure of olfactory nerve cells to the environment and may have a bearing on why sex differences favoring females have been observed at different points during the menstrual cycle (i.e., ovulation vs. menstruation; see Doty, Snyder, Huggins, \& Lowry, 1981; Parlee, 1983). Finally, olfactory neurons are primarily ipsilateral in projection, as opposed to the typical contralateral neural hardwiring. Given the number of atypical neurological and perceptual characteristics of olfaction, we might expect olfactory memory to be different from memory associated to visual or verbal stimuli. The following review is aimed at investigating this proposition.

\section{MEMORY FOR ODORS}

To date, olfactory recall has not been possible to study empirically because of the difficulty in producing observable recall output using cognitive-behavioral measures. Thus, our discussion of memory for odors is restricted to work on odor recognition memory. In a typical experiment, a subject is presented with a set of target odors and, at some later time, chooses between targets and distractors the "old" and "new" odors. Importantly, the similarity between the target and the distractor odor (e.g., grape vs. watermelon, or grape vs. turpentine) and the size of the distractor set in which the target is embedded substantially influence memory success. The more similar the distractors and the larger the distractor set, the more difficult odor recognition memory is (Engen, 1987). It is well known that set size and target-to-distractor similarity are general factors in recognition. Nevertheless, there is evidence that memory for odors may be distinct in other ways.

In this section, we review the research on memory for odors, with a focus on the characteristics that seem atypical in contrast to visual-verbal memory performance. For operational definition, olfactory items are volatile substances variously presented for subjects to smell without any other sensory identification (i.e., no accompanying visual or tactile cues). Visual items are objects, shapes, or nonlinguistic patterns shown to subjects. Verbal items are words or language symbols presented in either auditory or written form.

\section{Verbal Mediation}

The most contentious issue in human olfactory processing is the role of verbal mediation - that is, the extent to which linguistic and associative semantic processing occurs during olfactory sensory processing, and what its importance to higher levels of olfactory cognition is. A number of researchers have claimed that verbal codes are operative in odor memory to a degree comparable to visual and verbal memory. However, there is also considerable behavioral and neurological evidence that verbal mediation is not present and/or not essential. This issue is of theoretical significance, because if olfaction were not dependent on verbal mediation, this would demonstrate a profound difference between olfactory cognition and cognition mediated by other modalities.

Evidence for verbal mediation. Studies supporting the view that verbal mediation is inherent to olfactory processing have shown that (1) familiar and correctly identified odors are better remembered than are unfamiliar and incorrectly identified odors (Rabin \& Cain, 1984), (2) odor labeling can promote better odor memory (Lyman \& McDaniel, 1986, 1990), (3) odor names are a powerful context for odor perception (Batic \& Gabassi, 1987; Dubose, Cardello, \& Maller, 1980; Gabassi \& Batic, 1987; Herz, 1992; Moskowitz, 1979), and (4) verbal distractor tasks can interfere with short-term memory for odors (Gilmore, 1991; Murphy, Cain, Gilmore, \& Skinner, 1991; Perkins \& Cook, 1990). We review representative experiments in detail below.

Rabin and Cain (1984) examined memory for odors as a function of odor familiarity. Forty-five subjects were presented with 20 familiar odors (e.g., chocolate, popcorn, shoe polish) and told to provide a familiarity rating and name for each one. After three retention intervals ( $10 \mathrm{~min}, 1$ day, 7 days), subjects were asked to identify the 20 original odors from a set of 40 . Correct and consistent labeling and high ratings of familiarity at exposure were positively correlated with successful recognition. In a similar study, Lyman and McDaniel (1986) tested 48 
subjects with 30 odors. Subjects were to perform one of four encoding tasks during odor presentation: (1) visually imagining each odor, (2) attempting to name each odor, (3) associating each odor to a personal life event, or (4) simply smelling each odor. A recognition test administered 7 days later showed that subjects who had provided odor names or odor associations during encoding had the best recognition memory.

In an examination of short-term memory for odors, subjects performed one of four distractor tasks during the retention interval $(26 \mathrm{sec})$ between odor presentation and a four-alternative forced-choice recognition test (Walk \& Johns, 1984). The four tasks were as follows: (1) smelling a distractor odor and making verbal associations to it; (2) making verbal associations to the name of a distractor odor; (3) making verbal associations to the name of a target odorant; and (4) no instructions. Odor recognition was best when verbal associations were made to the target odor during retention. Furthermore, there was no difference in performance between verbalizing to the name of the distractor alone and smelling and verbalizing to the distractor. Perkins and Cook (1990) also found that verbal suppression, in the form of an auditory shadowing task (subjects heard, via headphones, a random series of digits that they had to repeat), interfered with odor recognition memory for a set of 15 target odors embedded within 15 distractor odors tested at both $10 \mathrm{~min}$ and 1 week postacquisition.

Verbal mediation in odor processing may change with age. Murphy et al. (1991) showed that a backwardcounting distractor task was more likely to disrupt visual and odor recognition by elderly subjects than by young adults. Such effects may reflect a greater dependence of elderly subjects on verbal cues. This result is consistent with other evidence showing the elderly's reduced ability for abstract and perceptual encoding and increased dependence on verbal codes (Craik \& McDowd, 1987). However, olfactory sensory deficits among the elderly (Doty et al., 1984) may also diminish processing at both encoding and retrieval.

The role demonstrated for verbal mediation during olfactory encoding can be explained by verbal encoding principles. It has long been shown that the more about an item that is encoded during learning, the more elaborate and/or deeper the memory trace for that item will be (e.g., Craik \& Lockhart, 1972; Craik \& Tulving, 1975). Thus, multisensory encoding (e.g., verbal and sensory) should strengthen the memory trace. Indeed, in olfaction, verbal encoding may actually supersede sensory encoding. Batic and Gabassi (1987) found that when odor names were provided with olfactory stimuli, memory for the odors was determined almost exclusively by the names, even when odor blanks were presented and when the odor and name given were mismatched. There are also many practical instances of this phenomenon. For example, a fragrance presented with a brand label is preferred over a fragrance presented without a label (Moskowitz, 1979). Likewise, people will misidentify purple-colored apple juice as a grape drink (Dubose et al., 1980). Overall, the data supporting the influence of verbal mediation in olfactory cognition suggest that once verbal/semantic information is available, odors are processed accordingly. This processing bias likely reflects our high verbal fluency in comparison with our sparse odor perceptual vocabulary (discussed in more detail below), as well the inherent human tendency to try to identify and categorize the perceptual world into stored prototypes (Fiske \& Taylor, 1984).

Evidence against verbal mediation. In contrast to the evidence implicating a fundamental role for verbal mediation in olfactory cognition, there are many sources of data that suggest little or no involvement of verbal processing in olfactory cognition.

In the first short-term odor memory experiment (Engen, Kuisma, \& Eimas, 1973), a backward-counting (i.e., verbal) interference task between presentation and test was shown to have no effect on odor recognition. Subjects smelled an odor and then began counting backward for four variable delays between 3 and $30 \mathrm{sec}$. Subjects were then presented with either the inspected odor or a foil and were to judge whether it was "old" or "new." This procedure was repeated for a diverse set of 100 odors. The results showed that about $82 \%$ of the odors were correctly recognized, and this percentage did not vary across retention intervals.

Several experiments in which odor familiarity ratings and odor labeling data were obtained have also failed to demonstrate verbal mediation in olfactory memory. Engen and Ross (1973) and Lawless and Cain (1975) showed that neither providing subjects with verbal odor labels nor having subjects generate verbal odor labels produced any advantage on subsequent odor recognition tests. In Engen and Ross' study, three experiments were conducted to examine long-term odor recognition memory. In the first experiment, subjects rated 48 odors for familiarity and were then given a forced-choice recognition test for the odors initially presented at four different time intervals (immediate, 1 day, 1 week, 1 month). In the second experiment, subjects were presented with 20 odors and were asked to provide a verbal association to each-preferably, the odor name. Odor recognition memory was then tested after 3 months using a two-alternative forced-choice procedure. In the third experiment, subjects were required to match 20 odors to either generic (wintergreen) or brand names (Life Savers), and a forced-choice recognition procedure was used at test 3 months later. The overall result from these three experiments was that the forgetting curve for odors was virtually flat over the 3-month retention interval (see The Shape of Long- and Short-Term Odor Memory section, below) and that neither odor familiarity nor odor labeling, whether self-generated or experimentally provided, had any effect on subsequent recognition memory.

In an experiment by Lawless and Cain (1975), two groups of subjects ( $n=20$ in each group) rated 11 odors for familiarity. One group also generated personally mean- 
ingful labels for each odor, and the other group rated the pleasantness of each odor. Subjects were then tested for their recognition of the original 12 odors from a set of 22 odors at $10 \mathrm{~min}, 1$ day, 1 week, and 1 month. Results showed a very slow decay in memory from $85 \%$ correct recognition at $10 \mathrm{~min}$ to $75 \%$ correct recognition at 1 month. Most strikingly, for the issue of verbal mediation, there were no differences in recognition performance between the odor-labeling and pleasantness-rating groups, nor was odor memory affected by rated odor familiarity.

The findings that odor naming and odor familiarity have no effect on subsequent odor recognition memory are in conflict with the data previously discussed (e.g., Lyman \& McDaniel, 1986, 1990; Rabin \& Cain, 1984). Methodological discrepancies may be pertinent to these differences. For example, at least some of the studies that failed to find evidence for verbal mediation used forcedchoice methods (e.g., Engen et al., 1973; Engen \& Ross, 1973) rather than the relatively more complex task of odor identification from large sets with distractors (e.g., Lyman \& McDaniel, 1986; Perkins \& Cook, 1990).

Our weak ability to provide verbal labels for odors may also account for some of the failure to find evidence for verbal mediation. Identification of very familiar odors is usually poor and rarely exceeds $50 \%$ (Cain, 1979); although English dictionaries contain several hundred entries applicable to odor quality (Moskowitz \& Gerbers, 1974), our language is devoid of any but the simplest abstract verbal categories for odors-those denoting hedonic value (good, bad), but not quality per se. The prototypic example is the case when someone can say that a particular odor is very familiar, can tell its likely source, and can name similar odors but cannot name the odor itself (Lawless \& Engen, 1977). This has been called the tip-of-the-nose state, after its verbal cousin. However, the tip-of-the-nose state is very different linguistically from the tip-of-the-tongue state (Brown \& McNeill, 1966). Unlike the tip-of-the-tongue situation, in the tip-of-thenose state, one has no lexical access to the odor name, such as first letter, general word configuration, or the number of syllables.

Importantly, it has been found that even when odors are difficult or impossible to verbally identify, they can act as reliable cues for complex memories (Herz \& Cupchik, 1992). In a study by Herz and Cupchik (1992), subjects reported full-blown episodic memories to odors they could not name (either idiosyncratically or correctly) in about $32 \%$ of cases. A corollary is the obser- vation that most odors are given personal, contextual labels (indicative of memorial associations) rather than invariant source names (Engen, 1987). For instance, it is far more likely for someone to call the smell of pine encountered indoors "Vicks Rub" or "cleaning solution" than to say "pine" (Herz \& Cupchik, 1992). However, that same odorant might be called "pine" if smelled outside or, depending on the culture and time of year, "Christmas." Whether an odor will evoke its specific source name (e.g., pine) turns out to be dependent on the extent to which it was named as such prior to presentation (Eich, 1978). This rule should then follow for any odor-name association. Thus, although words can be part of odor memory, their role appears to be dependent on prior experience.

Neurological research provides further evidence that verbal codes are relatively unimportant for olfactory $\operatorname{cog}$ nition. Goodglass, Barton, and Kaplan (1968) compared naming ability for visual, tactile, auditory, and olfactory stimuli in aphasic, right-brain-injured, and normal subjects. As expected, aphasics were significantly impaired relative to the two other groups. Interestingly, however, naming ability was worse for olfactory items than for items in other modalities, even though olfactory perception was unimpaired. These findings suggest that the link between language and sensation may be weaker in olfaction than it is for the other senses - thus making it more vulnerable to linguistic challenges - and that sensory and verbal processing of odors may be independent (detection vs. naming).

Conclusions. The cognitive experimental data for and against verbal mediation in olfactory memory are fairly evenly split. Experiential, linguistic, and neurological evidence, however, inclines us to believe that verbal codes have a nonessential role in olfactory cognition. However, an objective conclusion regarding the involvement of verbal codes in olfactory memory needs to be based on direct experimental investigations, and these have not yet been conducted. With the future implementation of crossmodal experiments and neuroimaging techniques, the role of verbal mediation in olfactory processing should be able to be determined (see Assessment of a Multiple Memory Systems Approach... section, below).

\section{The Shape of Long- and Short-Term Odor Memory}

Early research on odor memory revealed a retention function with essentially a 0 slope - quite different from that characteristic of visual or verbal memory. Although immediate performance was less than perfect (between $70 \%$ and $85 \%$ retention), there was almost no further forgetting in subsequent tests both in the short term $(30 \mathrm{sec})$ and long term (1 year) (Engen et al., 1973; Engen \& Ross, 1973; Jones, Roberts, \& Holman, 1978; Lawless \& Cain, 1975).

Engen and Ross's (1973) long-term odor memory experiment was modeled after Shepard's (1967) picture recognition memory study. The results revealed that recognition memory for odors was only $70 \%$ immediately following inspection, but that performance did not decline across four retention intervals. Even after a period of 1 year ( 15 subjects were available for follow-up testing), recognition performance was only $5 \%$ lower than what it had been immediately following acquisition (Engen \& Ross, 1973). Subsequent studies by Lawless and Cain (1975), Lawless and Engen (1977), and Rabin and Cain (1984) confirmed that odor memory declines only minimally over at least 28 days. Murphy et al. (1991) reported that over a 6-month period, odor memory in 
young adults declined only slightly, resembling the pattern of performance found earlier by Engen and colleagues. However, they similarly found that memory for symbols and faces remained about the same over a 6month period when tested the same way.

Only one published study has reported a decline in longterm odor memory similar to verbal forgetting: Perkins and Cook (1990) found that, with three different suppression tasks (verbal, visual, verbal + visual), subjects recognized significantly fewer odors 1 week postacquisition (delayed condition) than they did $10 \mathrm{~min}$ postacquisition (immediate condition). These researchers, however, found no difference between delayed and immediate odor recall memory, where subjects had to write down the names of as many odors as they could remember from the acquisition phase. It is unclear how the recall data should be interpreted because it was ostensibly a measure of odor name memory and not actual odor memory.

It has been suggested that the durability of long-term odor memory is caused by a negligible influence of retroactive interference (RI) in odor memory despite strong proactive interference (PI) effects (Engen, 1987; Lawless, 1978). This proposition stemmed from the results of a study that tested the effects of RI and PI in odor memory (Lawless \& Engen, 1977). The study was divided into three sessions. In the first session, subjects saw 12 pictures paired with a different odor for $1 \mathrm{~min}$ each. In the second session, $48 \mathrm{~h}$ later, the odor and pictures were represented, using either the same pairing (practice group) or a different pairing $\left(\mathrm{A}-\mathrm{B}, \mathrm{A}-\mathrm{B}_{\mathrm{r}}\right.$ design). In the final test session, 2 weeks later, subjects were given a 12 alternative forced-choice odor-picture matching test (all pictures were presented in full view). Subjects in the PI group were tested for their memory for the second session pairings, and subjects in the RI group were tested for their memory of the first session pairings. Compared with subjects in the practice group, subjects in the PI group were substantially worse at making correct matches. By contrast, subjects in the RI group did not reliably differ from the practice group. These results demonstrate that once an association to an odor is formed, it is difficult to subsequently form a different association to the same odor.

The explanation that has been offered for this effect is that, unlike words that are redundantly represented in multiple hierarchies of semantic-associative networks (e.g., Collins \& Loftus, 1975), odors are represented in memory as unitary, distinctive events with little attribute redundancy. This limits acquisition, but it results in minimal loss over time due to low rates of interference from similar stimuli (Engen, 1987; Lawless, 1978). To date, this interpretation for the influence of odor RI and PI and its relation to long-term odor memory has not been experimentally refuted.

Note that memory for pictorial stimuli, especially faces and abstract forms, is also well retained over long periods of time (e.g., Bevan \& Steger, 1971; Murphy et al., 1991; Nickerson, 1968). In particular, items that are difficult to encode seem to be well remembered (Pezdek et al., 1988). Cain and Gent (1986) have suggested that odor and face perception may be similar, in that both may depend on feature encoding. Thus, certain interference and encoding mechanisms may have general effects on long-term memory storage independent of the sensory modality through which information is perceived. What may separate olfaction from other sensory experiences is that regardless of an odor's complexity, once it is encoded, it appears to be indefinitely remembered (Engen, 1991).

Storage and decay processes in short-term odor memory have not yet been well defined. Some researchers have even suggested that a short-term odor memory store may not exist (Gabassi \& Zanuttini, 1983). Gabassi and Zanuttini (1983) offered this conclusion after finding no evidence of primacy or recency effects in shortterm odor memory. Twenty subjects were presented with 12 odors for $3 \mathrm{sec}$ each. After a short delay, subjects were given a two-alternative forced-choice recognition test. Recognition scores were positively correlated with odor familiarity, but no primacy or recency effects were seen.

Other researchers, however, have reported evidence for olfactory short-term memory and decay. Walk and Johns (1984) showed that short-term odor memory declined in the typical verbal fashion following an odor distractor task. Additionally, White (1992) found a serial position effect in short-term odor memory, suggesting a descending memory function. In White's experiment, recognition memory for five words and five odors was tested in 12 subjects. The typical primacy and recency effects were found for words, but only a recency effect was shown for odors.

An important feature of olfaction is that it is slower than visual or verbal processing (Laing \& MacLeod, 1992). Although some studies have taken this variable into account, the resultant data have still been ambiguous. For example, Gilmore (1991) observed that a verbal distractor task lasting $120 \mathrm{sec}$ reduced odor memory, whereas $30 \mathrm{sec}$ had no effect. However, Jones et al. (1978, Experiment 2) found no evidence that varying retention intervals, by the number of intervening target and distractor odors (between 1 and 15), had any impact on subsequent odor recognition memory.

Conclusions. The empirical data on long-term odor memory suggest that long-term odor memory may be distinguished from memory for other stimuli by being unusually resistant to decay. By contrast, the few and assorted findings on short-term odor memory make conclusions about the shape and duration of short-term odor memory currently impossible. Because olfactory memory appears to be exceptionally sensitive to methodological manipulations, protocols that take into account both the special features of olfaction (slower processing) and the appropriate cross-modal controls will have to be devised before the odor memory retention function can be determined and legitimately compared with visualverbal memory.

\section{Olfactory Recall and Imagery}

Imagery is a percept-like representation of a stimulus in the absence of sensory receptor stimulation. This def- 
inition assumes that perception and imagery share some of the same neural mechanisms (Farah, 1989; Finke, 1989; Hebb, 1968). Imagery is readily shown in vision and audition (see Finke, 1989, for a general discussion) and, to a lesser extent, in touch (shivers, tingles, phantom limb) and taste (sour reaction). Owing to the difficulty in reproducing an olfactory sensation in a manner that is experimentally verifiable or reliable, however, olfactory imagery has eluded definitive observation. Moreover, a recent survey study conducted on 140 undergraduates (Herz, 1996) showed that people consider their ability to conjure an odor sensation, in the absence of the percept, to be poor and significantly worse than their ability to conjure the sensation of visual, touch, or auditory stimuli (taste was not examined).

Despite the empirical and experiential obstacles, several researchers have examined the putative effects of olfactory imagery on olfactory memory. Lyman and McDaniel (1990, Experiment 2) compared the effects of olfactory imagery (imagine the smell of a banana) and visual imagery instructions (imagine the visual image of a banana) on the subsequent recognition of odors and pictures of odor referents. The results revealed that olfactory imagery instructions led to higher $d^{\prime}$ for odors, and visual imagery instructions led to higher $d^{\prime}$ for pictures. Encoding with the instruction to form an olfactory image of an odor aided odor recognition memory more than visual imagery instructions did, suggesting that olfactory imagery may be operative as it is in other modalities (see Finke, 1989). However, this effect was not observed when hit-rate scores were examined. The imagery results were therefore dependent on differences in falsealarm rates as a function of different encoding strategies, and, as such, it is questionable how meaningful they are. With this in mind, the most probable explanation for Lyman and McDaniel's findings is that olfactory verbal codes (as opposed to olfactory sensory codes) were activated by the odor imagery instructions, and these codes were more closely associated to olfactory experience than visual imaginal codes were (Paivio, 1986).

Olfactory imagery has also been examined in relation to perceptual performance. In three experiments - each testing a different method for assessing olfactory imagery (Experiment 1, selective interference tasks on odor recognition; Experiment 2, odor imagery vs. visual imagery on odor identification; Experiment 3, odor imagery vs. no imagery on odor detection) - Crowder and Schab (1995) found no advantage, or effects, as a function of odor imagery. In contrast to Lyman and McDaniel (1990), Crowder and Schab (1995) concluded that odor imagery did not facilitate olfactory perception or memory.

In an effort to diminish reliance on verbal processing in odor imagery testing, Carrasco and Ridout (1993) used multidimensional scaling techniques to determine whether common elements underlie olfactory perception and imagery. Depending on how many dimensions the solution space accounted for, similarities in olfactory imagery and perception were more or less apparent, but a generalized olfactory-imagery relationship did not emerge. Moreover, multidimensional scaling is a rather indirect (correlational) means for assessing olfactory imagery and is still inherently dependent on semantic associations (fruitiness, spiciness, familiarity, etc., are labeled factors).

On balance, these data imply that our ability to image odors is poor. Evolutionary principles might explain such a scenario: Olfaction originally evolved for the simple purpose of detecting and discriminating good from bad upon stimulus contact, and this function may not have required developing "mental representations" (Davis \& Ludvigson, 1995). Nevertheless, there is no a priori reason to believe that olfactory imagery does not exist in human brains where mental representations are stored in a variety of ways (Paivio, 1986). Furthermore, a general criticism of the extant imagery experimentation is that the procedures were likely to elicit olfactory semantic associations, and these may have overshadowed olfactory sensory codes. A less semantically loaded method for accessing olfactory imagery might be the use of implicit memory methods. Schab and Crowder (1995) explored implicit tests of odor memory using a repetition priming paradigm with odors as stimuli. In one experiment, 10 odors + names and 10 odor blanks + names (i.e., names only) were presented to subjects. Five minutes later, subjects were given an odor identification test for 30 odorants; the original 20 (odor + name condition, name-only condition) plus 10 new odors (control condition). Identification performance was best and fastest for stimuli from the original odor + name condition, and worst for new odors, suggesting a priming effect in odor perception based on prior olfactory coding. Although this finding does not demonstrate olfactory imagery, it does suggest that olfactory perception could be tapped into by using implicit memory methods.

Conclusions. In our opinion, implicit memory methods and neurological imaging techniques will be the key to determining whether olfactory imagery or recall exist, and whether their effects on cognition are comparable to sensation (see Assessment of a Multiple Memory Systems Approach... section, below). According to the imagery hypothesis (Farah, 1989; Finke, 1989; Hebb, 1968), imagery should activate the same neural areas as sensation/ perception, and thus neurological scans should show a high degree of overlap between these two tasks. Positron emission tomography studies have recently shown that visual imagery activates the same neural areas as visual perception - namely, the primary visual cortex (Kosslyn, Thompson, Kim, \& Alpert, 1995). The question now is whether similar neuroanatomical overlap can be shown for olfaction.

\section{Neurophysiological Correlates of Odor Memory Distinctiveness}

Studies on Korsakoff patients support the view that olfactory perception-memory functions are different from these operations mediated by the other senses. Mair, Capra, McEntee, and Engen (1980) compared Korsakoff patients and nonalcoholic controls for their ability to dis- 
criminate odors using a short-term recognition memory procedure. Subjects sampled an odorant and then performed a backward-counting task for delays of 5,15 , or $30 \mathrm{sec}$, after which they were to judge whether a second odor was the same or different from the one just sampled. Subjects also performed a signal detection task designed to measure absolute olfactory sensitivity. Although the ability to discriminate odors was significantly worse for Korsakoff patients than for controls, there was no evidence of decay in memory over the intervals tested for either group. This lack of decay in short-term odor memory was consistent with odor memory in normal subjects (Engen et al., 1973) and in stark contrast to the performance of these same patients on short-term memory tests for visual (faces) and verbal (consonant trigram) stimuli.

Korsakoff's syndrome is characterized by severe memory impairment. However, memory for odors was found to be less compromised than memory for visual or verbal items among these patients, although discrimination between odors was substantially worse than discrimination abilities for other sensory stimuli. This demonstrates that Korsakoff's syndrome disrupts the ability to discriminate between odorants, but this loss is not due to an inability to detect odors nor to a rapid decay of odor memory.

Perhaps differences in memory performance across stimulus types in Korsakoff patients reflect differential reliance on verbal processing. Korsakoff syndrome results in disruptions to frontal lobe function (see Kopelman, 1995, for a review). Among the frontal lobe functions that have been shown to be impaired are verbal fluency tasks (Jacobson \& Lishman, 1990; Kopelman, $1989,1991)$. Korsakoff patients also show impaired processing for verbal abstractions, such as pseudowords and pseudohomonyms, relative to alcoholic controls (Cermak, Verfaellie, Milberg, Letourneau, \& Blackford, 1991). Faces and consonant trigrams are similar to pseudoverbal stimuli in that they require the ability to form semantic abstractions in order to be remembered. Substandard memory for these stimuli among Korsakoff patients, relative to odor memory performance, may be due to impaired abstract verbal processing. That is, if odor memory processing does not require verbal abstractions, it should be relatively easier for these subjects to remember them. Interestingly, Korsakoff patients also show normal emotional memory (Douglas \& Wilkinson, 1993). It has been suggested that this is due to preserved amygdaloid circuit functioning, relative to impaired thalamic circuit functioning. Preserved emotional memory among these patients may have bearing on the robustness of odor memory, since olfaction and emotional memory processes seem to be specially associated (see Autobiographical Odor-Evoked Memory section, below).

\section{MEMORY EVOKED BY ODORS}

Modern experimentation concerned with odor-evoked memory has relied on either stimulus-response or asso- ciative learning procedures. In the former, odors are presented as stimuli and subjects are asked to report any memories that are spontaneously evoked (Herz \& Cupchik, 1992; Rubin, Groth, \& Goldsmith, 1984). In the latter, a single ambient odor is either present or absent during an incidental learning session for a series of tobe-remembered (TBR) items and the later recall session (e.g., Cann \& Ross, 1989; Ehrlichman \& Halpern, 1988; Herz, in press-b, in press-c; Schab, 1990; Smith, Standing, $\&$ de Man, 1992), or a set of odors is paired with a set of TBR items and memory for each item is then individually tested by cued recall (Davis, 1975, 1977; Eich, 1978; Herz \& Cupchik, 1995).

\section{Autobiographical Odor-Evoked Memory}

Odor-evoked memories have long been anecdotally described as "better" or more intense than memories evoked by other cues (e.g., Herz \& Cupchik, 1992; Laird, 1935; Rubin et al., 1984). Until recently, however, it has not been clear what the special features that make odor-evoked memories seem especially good are. Several experiments have now revealed that odors are actually equivalent to other cues for eliciting the veridical content of memory, but that odors evoke memories that are more emotionally loaded than are memories elicited through other modalities (Herz, in press-a; Herz \& Cupchik, 1995).

In the first direct examination of odor-evoked memory, Herz and Cupchik (1995) used a paired-associated incidental learning paradigm to examine whether odors evoked more emotional memories than verbal cues. Sixteen emotionally evocative paintings (TBR items) were paired with 16 cues, either odors or verbal odor labels. Painting recall and associated emotional experiences were tested $48 \mathrm{~h}$ later by cued recall. The results showed that painting recall accuracy was equivalent with the two cue types, but that when a painting was recalled to an odor, there was more emotion elicited in the recollection, more emotions experienced, higher emotional intensity, and greater confidence in emotional memory than when recall was associated to a verbal cue. In a follow-up study (Herz, in press-a), cues represented in olfactory, tactile, or visual form (the smell of an apple, the feel of an apple, or the sight of an apple) were compared as memory associates to emotional paintings using the Herz and Cupchik (1995) methodology. Results again revealed that memory accuracy did not vary as a function of cue type; however, the results revealed that, of the three types of cues, odors led to the most emotionally potent memory experiences (Herz, in press-a). Together, these results demonstrate that odors are equipotent with other stimuli for inducing accurate event recollections, but that odors evoke memories that are more emotionally potent.

In sum, these data demonstrate that odors are not "better" memory cues, if better means producing the most accurate recall. Rather, odor-evoked memories are more emotionally potent than are other cue-elicited memories, and it seems this saliency produces the impression that 
odor memories are more real. Neuroanatomical evidence (e.g., the unique interconnections between the olfactory area and the amygdala-hippocampal complex of the limbic system) is consistent with the finding that odorevoked memories are more emotionally potent than are memories evoked by other cues.

\section{Context-Dependent Memory}

In addition to giving rise to especially emotional memories, odors have been shown to be unusually effective contextual memory cues. Context-dependent memory $(\mathrm{CDM})$ is based on the principle that environmental features encoded as part of a memory trace can facilitate memory for stored material when subsequently encountered (Tulving, 1983). In keeping with this proposition, the same ambient odor present at study and test has been shown to significantly enhance retrieval for items learned (Cann \& Ross, 1989; Herz, in press-b; Schab, 1990; Smith et al., 1992). The reproducibility of odor effects is noteworthy because CDM research is known for inconsistent findings in studies where other physical cues, such as colors, sounds, and physical environments, have been manipulated (Smith, 1988). It appears, then, that the sensory qualities of odors may be superior to the attributes of other stimuli for facilitating CDM.

It has recently been demonstrated that successful CDM experiments are dependent on a change in internal state (such as mood) occurring in the context dependent environment (Eich, 1989, 1995; Eich, Macaulay, \& Ryan, 1994). Thus, a possible explanation for the potency of odor context cues is that odors impact on internal emotional states more than do other cue types. Consistent with this proposition, Ehrlichman and Halpern (1988) showed that subjects recalled significantly more positive personal memories in the presence of a pleasant odor (almond) than in the presence of an unpleasant odor (pyridine). The presence of pyridine was also reported to significantly decrease self-rated mood among college women (Ehrlichman \& Bastone, 1992). Likewise, applying pleasant perfume-type fragrances reliably elevated mood in menopausal women (Schiffman, Sattely-Miller, Suggs, \& Graham, 1995).

Importantly, it seems that the hedonic and emotional responses an odor elicits are dependent on how it was first encountered. In organisms ranging from fruit flies to humans, almost all responses to odors have been shown to be based on associative learning principles with conditioning and extinction operating in the usual way (Davis \& Ludvigson, 1995; Engen, 1988; Stein, Ottenberg, \& Roulet, 1958; Sullivan \& Leon, 1986, 1987). Thus, if an odor is perceived as pleasant, it was first experienced in a pleasant context. Although this is a somewhat contentious point, we believe that only odors that have been learned as positive or negative through prior association can elicit the corresponding hedonic response. Novel odors, therefore, should not be hedonically distinguishable. Studies with young children support this view
(Engen, 1988; Stein et al., 1958). The exception is for odors that strongly stimulate intranasal trigeminal structures. These odors are likely to elicit immediate avoidance reactions because of their irritating quality. This makes good adaptive sense, since such compounds are often highly toxic.

On the basis of the primacy of associative mechanisms in olfactory learning and the uniquely intimate connection between olfaction and emotional neural substrates, Herz (1992) has proposed a theory to explain the formation of autobiographical odor-evoked memories: If an odor is first experienced in an emotionally salient context, it will become an especially effective cue for event recollection. The reasoning is as follows: (1) emotional experiences result in higher levels of activation in the amygdaloid complex, (2) the amygdala has been shown to be critical for emotional memory (Cahill et al., 1995; Cahill, Prins, Weber, \& McGaugh, 1994), and (3) olfactory neurons synapse directly into the amygdala. Thus, if odor encoding takes place in an emotionally heightened context, increased limbic activation may cause the connection between an odor and event to become more tightly fused (e.g., by possible long-term potentiation effects) than if encoding occurs in a nonemotional context. As a result of the specific odor-event integration that takes place during encoding, when that odor is later encountered, it can precipitate the memory of the target event as well as a cascade of emotional experience.

To examine the relationship between odor and emotion in memory, Herz (in press-c) investigated whether a heightened emotional state experienced during the encoding of information associated to an unfamiliar odor would enhance the effectiveness of that odor as a retrieval cue. Two experiments were conducted in which a distinctive ambient odor either was present during both the incidental learning session (for a list of 16 neutral nouns) and free recall retrieval session or was never present; subjects were either in an anxious or in a neutral mood during encoding. At retrieval all subjects were in a neutral mood. In Experiment 1, anxiety was induced in the laboratory by a "speech threat" manipulation. In Experiment 2, naturally occurring anxiety was exploited by testing students in a preexam state. The dependent measure was word recall. Consistent with previous studies (Cann \& Ross, 1989; Herz, in press-b; Schab, 1990; Smith et al., 1992), word recall was higher when an ambient odor was present at both encoding and retrieval than when no ambient odor cue was available. Notably, however, in Experiment 1, a trend for highest word recall was seen among subjects who had been anxious during encoding, and, in Experiment 2, this trend was confirmed. Subjects who were exposed to an ambient odor and who were in a preexam anxiety state during encoding recalled more words than did subjects in any other group. These data are evidence that heightened emotion experienced during encoding with an ambient odor can enhance the effectiveness of that odor as a cue to memory. 
This finding supports the theory that emotion is a key varable in the formation of autobiographical odorevoked memories.

\section{Conclusions}

The available data suggest that memories evoked by odors have several special and perhaps unique characteristics related to their emotional quality: (1) memories elicited by odors appear to be more emotionally potent than memories evoked by other sensory stimuli, (2) odors can elicit affect and associated memories by way of their hedonic properties, (3) contextually distinctive odors are especially good retrieval cues, possibly because they induce changes in affect, and (4) when salient emotion is experienced during encoding with an odor, the effectiveness of that odor as a memory cue is enhanced.

\section{THEORETICAL ANALYSIS}

A principal aim of this paper has been to assess whether and to what extent the principles that govern odor memory are distinguished from those that describe memory mediated by the other senses. The most pronounced singularities of odor memory appear to be in the evocativeness of odor-associated memory and its relation to emotion. Although not yet entirely confirmed, other distinguishing features are that olfactory sensory imagery seems to be weak or nonexistent, and long-term odor memory is unusually resistant to decay. Data from Korsakoff patients have also demonstrated that olfactory memory is preserved beyond other sense memories, which suggests that the neurological representation of odor memory is different from that of other sensory systems.

Our review, however, also makes it clear that there are a number of unresolved issues with respect to the distinctiveness of odor memory. The most important unsettled matters are (1) the contribution of verbal codes (Cain, 1980; Engen, 1987; Schab, 1991), (2) the shape of the short-term memory function, and (3) the factors that influence short- and long-term memory. Experimental inconsistencies appear to be at the root of these issues. Despite the debates in these areas, we believe there is more evidence in favor of the view that odor memory is different from, rather than similar to, visual-verbal memory. To test this proposition, we evaluated the literature using a multiple memory systems (MMS) analysis.

MMS theories generally presume that there are specialized types of memory governed by specific and distinct rules and underlying mechanisms. MMS frameworks have been discussed in different ways to apply to both conceptual and physiological memory functions (e.g., Nissen \& Knopman, 1987; Roediger, Rajaram, \& Srivinas, 1990; Schacter \& Tulving, 1994; Shallice, 1979; Sherry \& Schacter, 1987; Warrington, 1982). We used the criteria outlined by Roediger et al. (1990) and Sherry and Schacter (1987)-functional dissociation, stochastic independence, independent neural systems, and functional incompatibility-to assess whether odor memory can be considered a separate memory system.

\section{Functional Dissociation}

To satisfy the criteria of functional dissociation, divergent performance on a single variable (e.g., memory) for two or more types of tasks or tests must be shown. Currently, evidence for functional dissociations is demonstrated most clearly by Korsakoff patients. Among Korsakoff patients, odor discrimination is impaired, whereas odor memory remains intact. By contrast, memory mediated by other sensory modalities is severely disrupted, whereas discrimination is not much affected (Mair et al., 1980). Thus, different mechanisms appear to underlie olfactory memory and discrimination processes, not seen to the same extent in other sensory systems. Similarly, the verbal-perceptual dissociations shown by aphasics are more pronounced for olfactory stimuli than for stimuli in other senses (Goodglass et al., 1968). These instances of impaired versus spared dissociations are consistent with an MMS characterization.

\section{Stochastic Independence}

Stochastic independence between tests refers to a lack of correlation between different measures (e.g., memory) taken at the same time-for example, comparisons of the data from implicit and explicit memory measures from within the same experiment. No examination of odor memory has yet undertaken analyses at this level. Therefore, the criteria of stochastic independence remain indeterminate.

\section{Independent Neural Systems}

It is clear that each sense responds to different stimuli and that each is subserved by specific neural centers. However, as our earlier neuroanatomical review illustrated, the neural pathways and mechanisms mediating olfactory processing appear to be quite different from the neuroanatomical organization that subserves other sensory systems. Indeed, it has been suggested that the functional nature of the projections from the primary olfactory cortex to the orbital prefrontal cortex is unlike that of second-order projections from other sensory systems (Carmichael et al., 1994). For example, although the orbital cortex contains the first neocortical olfactory representation, it does not seem to serve a functional role analogous to that of primary visual, auditory, or somatosensory cortex (Carmichael et al., 1994).

Correspondingly, studies on multisensory integration have shown that vision, hearing, and touch have a greater propensity for cross-modal interaction and transfer with each other than does olfaction with these senses (Stein \& Meredith, 1990). As previously discussed, olfactory information is transmitted to the neocortex without thalamocortical relays and does not interact with other major sensory pathways. It has also been demonstrated that the superior colliculus integrates visual, auditory, and soma- 
tosensory input but not olfactory activity. In other words, vision, hearing, and touch are integrated, but olfactory input is excluded at a basic neurological level. Taken together with the special anatomical features of olfaction and the particular dissociations observed in Korsakoff patients and aphasics, the findings suggest that olfaction operates independently from other sensory systems in basic neurobiological terms.

\section{Functional Incompatibility}

Functional incompatibility in memory systems is an evolutionary concept that describes the observation that specialized solutions to specific environmental problems have evolved in particular organisms or systems, such that the functional problems handled by one system cannot be handled by another system (Sherry \& Schacter, 1987). On the basis of an evolutionary analysis of learning and memory over a wide range of species, Sherry and Schacter (1987) concluded that certain specialized variations of learning and memory have evolved that require specific and unique explanatory principles. Functional incompatibility in learning and memory is witnessed when different memory systems are characterized by different rules of operation. A key premise is that having different memory systems adapted to serve different environmental operations provides some evolutionary advantage (Sherry \& Schacter, 1987).

In all infrahuman mammalian species, it is evident that olfactory processing evolved to serve specific, biologically important roles. Olfaction is a higher order manifestation of primitive chemotaxis, and, even in complex vertebrates, it remains an important method of gathering information about the environment. Humans appear to be one of the few creatures for whom chemical signals are not central to biological purposes. Instead, our experience of odors is primarily hedonic or aesthetic (i.e., liking-disliking). Simple hedonic responses of this type have been equated by some emotion theorists to low-level affect, in the form of experienced pleasantness or unpleasantness (Hoffman, 1986; Livesey, 1986). It has correspondingly been proposed that emotion evolved to tell us what was good and what was bad to approach or avoid (Barash, 1982). In fact, emotions have been described by several theorists as behavioral adaptations to stimuli that threaten or abet our survival (e.g., Plutchik, 1980, 1994; Tooby \& Cosmides, 1990). Thus, the human experience of emotion can be considered to be the symbolic and abstract version of the same survival approach-avoid reactions that chemical cues elicit in other animals. In other words, the functional significance of odor and emotion is analogous and perhaps related. Moreover, from a neuroevolutionary perspective, the limbic system grew out of the olfactory bulb. Perhaps, then, our experience of emotion might be very different if we did not have the sense of smell.

The unique emotional potency of odor-evoked memories supports the functional incompatibility criterion for odor memory as a separate system. On the basis of the singularly direct neurological interconnections between odor and emotional neural substrates and the functional analogy between odor and emotion in evolutionary terms, it would seem that there is a special physiological preparedness for odors to acquire emotional significance beyond that of the other senses. Moreover, the primacy of emotion-based associative learning mechanisms is a special attribute of olfactory learning. The atypical potency of PI effects in odor memory supports this proposition and may also explain how learned "taste aversions" (Garcia \& Brett, 1977) develop and why they are so difficult to modify (Engen, 1982, 1987).

\section{ASSESSMENT OF A MULTIPLE MEMORY SYSTEMS APPROACH AND THE FUTURE OF ODOR MEMORY RESEARCH}

To support the claim that odor memory is a separate memory system, we would have to show that it is governed by specific and distinct rules and underlying mechanisms. Applying the MMS criteria as we have, we see that there were several limitations to our analysis. First, the MMS criteria could be addressed to only a subset of olfactory memory features, and then not entirely (i.e., stochastic independence). A second limitation is that the comparisons made were primarily concerned with differences between odor memory and visual-verbal memory and therefore cannot justifiably differentiate odor memory from all sensory memory systems. Moreover, a large portion of the evidence we marshall for the uniqueness of odor memory is based on ancillary neurological evidence rather than direct empirical testing. A conservative approach thus forces us to concede that we cannot yet determine whether odor memory is a separate memory system. Nevertheless, because of the numerous special features of olfaction that have clearly been shown, we believe that an MMS approach is the most constructive theoretical model for addressing the special properties of olfactory memory, organizing the extant data, and stimulating new research in this field.

Much of the uncertainty in the available cognitivebehavioral literature on olfactory memory can be attributed to methodological inconsistencies. Accordingly, the first step is to develop and implement a set of standard methods that yield replicable findings across laboratories. To determine whether odor memory is in fact a separate memory system or merely a different form of an extant memory system(s) (Schacter \& Tulving, 1994), cross-modal memory experiments addressing the issues we have discussed (e.g., verbal codes, short- and longterm memory, and imagery) are essential. Experiments in which the performance patterns for odor cues, touch cues, visual cues, and auditory cues of the same source objects (e.g., popcorn) on basic memory operations need to be conducted in tandem with experiments aimed at examining memory mediating variables. 
Context effects, both internal and environmental, have been shown to significantly influence performance on a variety of cognitive dimensions (e.g., see Bouton, 1993, and Davies \& Thomson, 1988, for some reviews). Given the known susceptibility of olfactory perception to context (e.g., verbal labels), the effects of context on olfactory memory are expected to be strong. An examination of the manner in which context effects interact with the formation and reinstatement of memories associated to stimuli in different sensory modalities would be highly beneficial. We also strongly encourage cross-modal investigations of qualitative stimulus dimensions, such as pleasantness, complexity, intensity, and familiarity. We believe that, by applying this strategy with systematic research, the similarities and differences between odor memory and memory meditated through other faculties can be reliably established, and the special attributes of odor memory can be specifically detailed.

In view of the theoretical significance of verbal mediation in olfactory memory, it will also be important to delineate the verbal dimensions of different sensory cue types (e.g., touch, vision, and audition) in contrast to olfaction and to use both verbalizable and nonverbalizable test materials. Similarly, further work aimed at elucidating the asymmetric relation between sensation and cognition in olfaction (i.e., recall and imagery) in comparison with the other senses will be important for interpreting the role of verbal mediation in odor memory.

In our opinion, the application of neuroimaging techniques will make the greatest contribution toward resolving many of the current ambiguities in the odor memory literature and will promote significant advancements for the field of olfactory science in general. Zatorre, Jones-Gotman, Evans, and Meyer (1992) have demonstrated functional localization of human olfactory cortex using positron emission tomography. Another widespread neuroimaging technique is functional magnetic resonance imaging (MRI). Functional MRI has already been used to study olfactory localization (Ramsey et al., 1994) and may be more experimentally feasible than positron emission tomography methods. Functional MRI is a noninvasive neuroimaging technique that relies on local variation in blood supply and $\mathrm{O}_{2}$ concentration during neural activity (Ogawa, Lee, Nayak, \& Glynn, 1990; Turner, Le Bihan, Moonen, Despres, \& Frank, 1991). With functional MRI, repeated images of the same brain region are obtained over very brief intervals, thus making it possible to image real-time mental events. Using functional MRI, it would be possible to examine the brain areas that are activated during odor imagery (e.g., imagining the smell of a rose) compared with those activated during odor sensory experience (e.g., smelling a rose). Thus, the degree of overlap between these two functions in comparison with the same tasks undertaken through another modality, such as vision, could be directly ascertained. Neuroimaging methods would similarly make it possible to directly examine the verbal and nonverbal dimensions of odor perception and memory, as well as the cortical areas activated by emotional or nonemotional odor-evoked memory experiences.

Research exploiting the special attributes of olfaction will also inform related areas in cognitive psychology and neuroscience. For example, the use of odors as memory cues has suggested that a dissociation between emotional experience and memory content can be demonstrated in episodic memory (Herz \& Cupchik, 1995). Future experiments using odors as cues for investigating emotional memory may be able to elucidate the nature and extent of this dissociation and profit emotional memory research in this domain.

It is certain that the senses all share a number of commonalities. Yet it is also certain that there are unique properties of each sensory system, and it seems that odor memory in particular may be different. Future investigations into the similarities and differences of odor memory with other perceptual systems using cross-modal paradigms combined with neurological imaging and human clinical populations should resolve many of the questions that currently remain unanswered. We anticipate that integrating these methods with cognitive and neurobiological theory will provide the basis for a comprehensive theory that is ultimately able to account for memory mediated by all systems and all sensory realms.

\section{REFERENCES}

Aggleton, J. P., \& Mishrin, M. (1986). The amygdala: Sensory gateway to the emotions. In R. Plutchik \& H. Kellerman (Eds.), Emotion: Theory, research and experience. Vol 3: Biological foundations of emotion (pp. 281-296). Orlando, FL: Academic Press.

Barash, D. P. (1982). Sociobiology and behavior (2nd ed.). New York: Elsevier

Batic, N., \& Gabassi, P. G. (1987). Visual dominance in olfactory memory. Perceptual \& Motor Skills, 65, 88-90.

Bevan, W., \& Steger, J. A. (1971, February 8). Free recall and abstractness of stimuli. Science, 172, 597-599.

Bolger, E. M., \& Tichener, E. B. (1907). Some experiments on the association power of smells. American Journal of Psychology, 18, 326-327.

Bouton, M. E. (1993). Context, time and memory retrieval in the interference paradigms of Pavlovian learning. Psychological Bulletin, 114, 80-99

Brown, R. W., \& McNeill, D. (1966). The "tip of the tongue" phenomenon. Journal of Verbal Learning \& Verbal Behavior, 5, 325327.

Cahill, L., Babinsky, R., Markowitsch, H. J., \& McGaugh, J. L. (1995). The amygdala and emotional memory. Nature, 377, 295-296.

Cahill, L., Prins, B., Weber, M., \& McGaugh, J. L. (1994). Betaadrenergic activation and memory for emotional events. Nature, 371, 702-704.

CaIN, W. S. (1979, February 2). To know with the nose: Keys to odor identification. Science, 203, 467-470.

CAIN, W. S. (1980). Chemosensation and cognition. In H: van der Starre (Ed.), Olfaction and taste VII (pp. 347-357). London: IRL.

CAIN, W. S., \& GENT, J. F. (1986). Use of odor identification in clinical testing of olfaction. In H. L. Meiselman \& R. S. Rivlin (Eds.), Clinical measurement of taste and smell (pp. 170-186). New York: Macmillan

CANN, A., \& Ross, D. A. (1989). Olfactory stimuli as context cues in human memory. American Journal of Psychology, 102, 91-102.

Carmichael, S. T., Clugnet, M. C., \& Price, J. L. (1994). Central olfactory connections in the macaque monkey. Journal of Comparative Neurology, 346, 403-434. 
Carrasco, M., \& Ridout, J. B. (1993). Olfactory perception and olfactory imagery: A multidimensional analysis. Journal of Experimental Psychology: Human Perception \& Performance, 19, 287-301.

Cermak, L. S., Verfaillie, M., Milberg, W., Letourneau, L., \& BLACKFoRd, S. (1991). A further analysis of perceptual identification priming in alcoholic Korsakoff patients. Neuropsychologia, 29, 725-736.

Collins, A. M., \& Loftus, E. F. (1975). A spreading activation theory of semantic processing. Psychological Review, 82, 407-428.

CraIK, F. I. M., \& LOCKHART, R. S. (1972). Levels of processing: A framework for memory research. Journal of Verbal Learning \& Verbal Behavior, 11, 671-684.

Craik, F. I. M., \& MCDowd, J. M. (1987). Age differences in recall and recognition. Journal of Experimental Psychology: Learning, Memory, \& Cognition, 13, 474-479.

Craik, F. I. M., \& Tulving, E. (1975). Depth of processing and the retention of words in episodic memory. Journal of Experimental Psychology: General, 104, 268-294.

Crowder, R. G., \& SCHAB, F. R. (1995). Imagery for odors. In R. G. Crowder \& F. R. Schab (Eds.), Memory for odors (pp. 93-107). Hillsdale, NJ: Erlbaum.

Davies, G. M., \& Thomson, D. M. (1988). Memory in context: Context in memory. Toronto: Wiley.

Davis, R. G. (1975). Acquisition of verbal associations to olfactory stimuli of varying familiarity and to abstract visual stimuli. Journal of Experimental Psychology: Human Learning \& Memory, 1, 134-142.

Davis, R. G. (1977). Acquisition and retention of verbal associations to olfactory and abstract visual stimuli of varying similarity. Journal of Experimental Psychology: Human Learning \& Memory, 3, 37-51.

Davis, S. F., \& Ludvigson, H. W. (1995). Odor memory in nonhumans. In R. G. Crowder \& F. R. Schab (Eds.), Memory for odors (pp. 133-158). Hillsdale, NJ: Erlbaum.

Doty, R. L., Shaman, P., Applebaum, S. L., Giberson, R., SiksorSKI, L., \& RosenBerG, L. (1984, December 21). Smell identification ability: Changes with age. Science, 226, 1441-1443.

Doty, R. L., SNyder, P., Huggins, G., \& Lowry, L. D. (1981). Endocrine, cardiovascular and psychological correlates of olfactory sensitivity changes during the human menstrual cycle. Journal of Comparative \& Physiological Psychology, 95, 45-60.

Douglas, J. J., \& Wilkinson, D. A. (1993). Evidence of normal emotional responsiveness in alcoholic Korsakoff's syndrome in the presence of profound memory impairment. Addiction, 88, 1637 1645.

Dubose, C. N., Cardello, A. V., \& Maller, O. (1980). Effects of colorants and flavorants on identification, perceived flavor intensity and hedonic quality of fruit-flavored beverages and cake. Journal of Food Science, 45, 450-458.

Ehrlichman, H., \& Bastone, L. (1992). The use of odour in the study of emotion. In S. Van Toller \& G. H. Dodd (Eds.), Fragrance: The psychology and biology of perfume (pp. 143-159). London: Elsevier.

Ehrlichman, H., \& Halpern, J. N. (1988). Affect and memory: Effects of pleasant and unpleasant odour on retrieval of happy and unhappy memories. Journal of Personality \& Social Psychology, 55, $769-779$

Elch, J. E. (1978). Fragrances as cues for remembering words. Journal of Verbal Learning \& Verbal Behavior, 17, 103-111.

Eich, [3.] E. (1989). Theoretical issues in state dependent memory. In H. L. Roediger III \& F. I. M. Craik (Eds.), Varieties of memory and consciousness: Essays in honour of Endel Tulving. Hillsdale, NJ: Erlbaum.

EICH, [J.] E. (1995). Searching for mood dependent memory. Psychological Science, 6, 67-75.

EICH, [J.] E., MaCauley, D., \& Ryan, L. (1994). Mood dependent memory for events of the personal past. Journal of Experimental Psychology: General, 123, 201-215.

Eichenbaum, H. (in press). Olfactory perception and memory. In R. Llinas \& P. Churchland (Eds.), The mind-brain continuum. Cambridge, MA: MIT Press.

Engen, T. (1982). The perception of odors. Toronto: Academic Press.
Engen, T. (1987). Remembering odors and their names. American Scientist, 75, 497-503.

ENGEN, T. (1988). The acquisition of odor hedonics. In S. Van Toller \& G. H. Dodd (Eds.), Perfumery: The psychology and biology of fragrance (pp. 79-90). New York: Chapman \& Hall.

ENGEN, T. (1991). Odor sensation and memory. New York: Praeger.

Engen, T., Kuisma, J. E., \& Eimas, P. D. (1973). Short-term memory of odors. Journal of Experimental Psychology, 99, 222-225.

ENGEN, T., \& Ross, B. M. (1973). Long-term memory of odors with and without verbal descriptions. Journal of Experimental Psychology, 100, 221-227.

FARAH, M. J. (1989). The neuropsychology of mental imagery. In J. W. Brown (Ed.), Neuropsychology of visual perception (pp. 183-202) Hillsdale, NJ: Erbalum.

Farbman, A. I. (1992). Cell biology of olfaction. New York: Cambridge University Press.

FINKE, R. A. (1989). Principles of mental imagery. Cambridge, MA MIT Press.

Fiske, S. T., \& TAYLOR, S. E. (1984). Social cognition. New York: Random House.

Gabassi, P., \& Batic, N. (1987). Interference processes in visual and olfactory stimulations. Perceptual \& Motor Skills, 65, 79-82.

Gabassi, P., \& ZanUtTini, L. (1983). Riconoscimento di stimoli olfattivi nella memoria a breve termine [Recognition of olfactory stimul in short-term memory]. Giornale Italiano di Psicologia, 10, 51-60.

GarCia, J., \& BrETt, L. P. (1977). Conditioned responses to food odor and taste in rats and wild predators. In M. R. Kare \& O. Maller (Eds.) The chemical senses and nutrition (pp. 277-290). New York: Academic Press.

GILMORE, M. M. (1991, April). On the encoding of odors: Is there a visual and/or semantic component? Paper presented at the 13 th annual meeting of the Association for Chemoreception Sciences, Sarasota, FL.

GoOdglass, H., Barton, M., \& KaPLAN, E. (1968). Sensory modality and object naming in aphasia. Journal of Speech \& Hearing Research, 11, 488-496.

Hebs, D. O. (1968). Concerning imagery. Psychological Review, 75, 466-477.

HERZ, R. S. (1992). The relationship between odor and emotional memory. Unpublished doctoral dissertation, University of Toronto.

HERZ, R. S. (1996). The importance of odor in interpersonal relationships among males and females with and without olfactory loss. Manuscript in preparation.

HERZ, R. S. (in press-a). A comparison of olfactory, tactile and visual stimuli as associated memory cues. Chemical Senses.

HERZ, R. S. (in press-b). The effects of cue distinctiveness and novelty on odor-based context dependent memory. Memory \& Cognition.

HERZ, R. S. (in press-c). Emotion experienced during encoding enhances odor retrieval cue effectiveness. American Journal of Psychology.

Herz, R. S., \& CupChik, G. C. (1992). An experimental characterization of odor-evoked memories in humans. Chemical Senses, 17, 519-528.

Herz, R. S., \& CuPChIK, G. C. (1995). The emotional distinctiveness of odor-evoked memories. Chemical Senses, 20, 517-528.

HeYwood, A., \& Votriede, H. (1905). Some experiments on the associative power of smells. American Journal of Psychology, 1, 32 1396.

Hoffman, M. L. (1986). Affect, cognition, and motivation. In R. M Sorrentino \& E. T. Higgins (Eds.), Handbook of motivation and cognition: Foundations of social behavior (pp. 244-280). New York: Guilford.

Insausti, R., Amaral, D. G., \& Cowan, W. M. (1987). The entorhinal cortex of the monkey: II. Cortical afferents. Journal of Comparative Neurology, 264, 356-395.

JACOBSON, R. R., \& LISHMAN, W. (1990). Cortical and diencephalic lesions in Korsakoff's syndrome: A elinical and CT scan study. Psychological Medicine, 20, 63-75.

Jones, F. N., RoberTs, K., \& Holman, E. W. (1978). Similarity judgments and recognition memory for some common spices. Perception \& Psychophysics, 24, 2-6. 
KENNETH, J. H. (1927). An experimental study of affects and associations due to certain odors. Psychological Review Publications, 37, 1-64.

KING, J. R. (1988). Anxiety reduction using fragrances. In S. Van Toller \& G. H. Dodd (Eds.), Perfumery: The psychology and biology of fragrance (pp. 147-165). New York: Chapman \& Hall.

Kopelman, M. D. (1989). Remote and autobiographical memory, temporal context memory, and frontal atrophy in Korsakoff and Alzheimer patients. Neuropsychologia, 27, 437-460.

Kopelman, M. D. (1991). Frontal lobe dysfunction and memory deficits in alcoholic Korsakoff syndrome and Alzheimer-type dementia. Brain, 114, 117-137.

Kopelman, M. D. (1995). The Korsakoff syndrome. British Journal of Psychiatry, 166, 154-173.

Kosslyn, S., Thompson, W., Kim, I., \& Alpert, N. (1995). Topographic representations of mental images in primary visual cortex. Nature, 378, 496-498.

LAING, D., \& MACLEOD, P. (1992). Reaction time for the recognition of odor quality. Chemical Senses, 17, 337-346.

LaIRD, D. A. (1935). What can you do with your nose? Scientific Monthly, 41, 126-130.

LAWLESS, H. T. (1978). Recognition of common odors, pictures, and simple shapes. Perception \& Psychophysics, 24, 493-495.

LAWLESS, H. T., \& CAIN, W. S. (1975). Recognition memory for odors Chemical Senses \& Flavour, 1, 331-337.

LAwLESS, H. [T.], \& ENGEN, T. (1977). Associations to odors: Interference, mnemonics, and verbal labeling. Journal of Experimental Psychology, 3, 52-59.

Levine, J. M., \& McBurney, D. H. (1986). The role of olfaction in social perception and behaviour. In C. P. Herman, M. P. Zanna, \& E. T. Higgins (Eds.), Physical appearance, stigma and social behaviour: The Ontario Symposium (Vol. 3, pp. 179-217). Hillsdale, NJ: Erlbaum.

LIVESEY, P. J. (1986). Learning and emotion: A biological synthesis. Vol. I: Evolutionary processes. Hillsdale, NJ: Erlbaum.

LYMAN, B. J., \& MCDANIEL, M. A. (1986). Effects of encoding strategy on long-term memory for odours. Quarterly Journal of Experimental Psychology, 38, 753-765.

Lyman, B. J., \& MCDANiEl, M. A. (1990). Memory for odors and odor names: Modalities of elaboration and imagery. Journal of Experimental Psychology: Learning, Memory, \& Cognition, 16, 656-664.

MaIR, R. G., CAPRA, C., McEnTEe, W. J., \& EnGen, T. (1980). Odor discrimination and memory in Korsakoff's psychosis. Journal of Experimental Psychology: Human Perception \& Performance, 6, 445-458.

MoskowITZ, H. R. (1979). Mind, body and pleasure: An analysis of factors which influence sensory hedonics. In J. H. A. Kroeze (Ed.), Preference behaviour and chemoreception (pp. 131-144). London: IRL.

Moskowitz, H. R., \& Gerbers, C. L. (1974). Dimensional salience of odors. Annals of the New York Academy of Sciences, 237, 1-16.

Murphy, C., Cain, W. S., Gilmore, M. M., \& Skinner, B. (1991). Sensory and semantic factors in recognition memory for odors and graphic stimuli: Elderly versus young persons. American Journal of Psychology, 104, 161-192.

NiCKERSON, R. S. (1968). A note on long-term recognition memory for pictorial material. Psychonomic Science, 11, 58.

Nissen, M. J., \& KNOPMAN, D. S. (1987). Neurochemical dissociation of memory systems. Neurology, 37, 789-794.

Ogawa, S., LeE, T. M., Nayak, A. S., \& GlynN, P. (1990). Oxygenationsensitive contrast in magnetic resonance image of rodent brain at high magnetic fields. Magnetic Resonance in Medicine, 14, 68-78.

PAIVIO, A. (1986). Mental representation: $A$ dual coding approach. New York: Oxford University Press.

PARLEe, M. B. (1983). Menstrual rhythms in sensory processes: A review of fluctuations in vision, olfaction, audition, taste and touch. Psychological Bulletin, 93, 539-548.

Pelosi, P. (1994). Odorant-binding proteins. Critical Reviews in Biochemistry \& Molecular Biology, 29, 199-228.

Perkins, J., \& COOK, N. M. (1990). Recognition and recall of odours: The effects of suppressing visual and verbal encoding processes. British Journal of Psychology, 81, 221-226.
Pezdek, K., Maki, R., Valencia-Laver, D., Whetstone, T., StoeckERT, J., \& Dougherty, T. (1988). Picture memory: Recognizing added and deleted details. Journal of Experimental Psychology: Learning, Memory, \& Cognition, 14, 468-476.

PLUTCHIK, R. (1980). Emotion: A psychoevolutionary synthesis. New York: Harper \& Row.

PlutchIK, R. (1994). The psychology and biology of emotion. New York: HarperCollins.

RABIN, M. D., \& CAIN, W. S. (1984). Odor recognition, familiarity, identifiability and encoding consistency. Journal of Experimental Psychology: Learning, Memory, \& Cognition, 10, 316-325.

Ramsey, N. F., Rawlings, R., Van Gelderen, P., Duyn, J. H., Moonen, D. W., \& Hommer, D. W. (1994). A 3-D functional MRI demonstration of brain structures involved in olfaction. Proceedings of the 24th Annual Meeting of the Society for Neuroscience, 20, 1474.

Robinson, D. A. (1968, September 20). Eye movement control in primates. Science, 184, 1219-1224.

Roediger, H. L., III, Rajaram, S., \& SRInivas, K. (1990). Specifying criteria for postulating memory systems. In A. Diamond (Ed.), The development and neural bases of higher cognitive functions (Annals of the New York Academy of Sciences, Vol. 608, pp. 572-595). New York: New York Academy of Sciences.

RuBin, D. C., GRorh, E., \& GoldSMITH, D. J. (1984). Olfactory cuing of autobiographical memory. American Journal of Psychology, 97, 493-507.

SCHAB, F. R. (1990). Odors and the remembrance of things past. Journal of Experimental Psychology: Learning, Memory, \& Cognition, 16, 648-655.

SCHAB, F. R. (1991). Odor memory: Taking stock. Psychological Bulletin, 109, 242-251.

SCHAB, F. R., \& CROwDER, R. G. (1995). Implicit measures of odor memory. In R. G. Crowder \& F. R. Schab (Eds.), Memory for odors (pp. 71-91). Hillsdale, NJ: Erlbaum.

SChacter, D. L., \& Tulving, E. (1994). What are the memory systems of 1994 ? In D. L. Schacter \& E. Tulving (Eds.), Memory systems 1994. Cambridge, MA: MIT Press.

Schiffman, S. M., SatTely-Miller, E. A., Suggs, M. S., \& Graham, B. G. (1995). The effect of pleasant odors and hormone status on mood of women at midlife. Brain Research Bulletin, 36, 19-29.

Schwerdtfeger, W. L., Buhl, E. H., \& Gemroth, P. (1990). Disynaptic olfactory input to the hippocampus mediated by stellate cells in the entorhinal cortex. Journal of Comparative Neurology, 194, $519-534$

SHALLICE, T. (1979). Neuropsychological research and the fractionation of memory systems. In L.-G. Nilsson (Ed.), Perspectives on memory research (pp. 257-278). Hillsdale, NJ: Erlbaum.

SHEPARD, R. N. (1967). Recognition memory for words, sentences, and pictures. Journal of Verbal Learning \& Verbal Behavior, 6, 156-163.

SHFRRY, D. F., \& SCHACTER, D. L. (1987). The evolution of multiple memory systems. Psychological Review, 94, 439-454.

Smith, D. G., Standing, L., \& DE Man, A. (1992). Verbal memory elicited by ambient odor. Perceptual \& Motor Skills, 74, 339-343.

SMITH, S. M. (1988). Environmental context-dependent memory. In G. M. Davies \& D. M. Thomson (Eds.), Memory in context: Context in memory (pp. 13-34). Toronto: Wiley.

Staubli, U., Ivy, G., \& LyNCH, G. (1984). Hippocampal denervation causes rapid forgetting of olfactory information in rats. Proceedings of the National Academy of Sciences, 81, 5885-5887.

STAUBLI, U., IVY, G., \& LYNCH, G. (1986). Studies on retrograde and anterograde amnesia of olfactory memory after denervation of the hippocampus by entorhinal lesions. Behavioral Neurology \& Biology, 46, 432-444.

Stein, B. E., \& Meredith, M. A. (1990). Multisensory integration: Neural and behavioral solutions for dealing with stimuli from different sensory modalities. In A. Diamond (Ed.), The development and neural bases of higher cognitive functions (Annals of the New York Academy of Sciences, Vol. 608, pp. 51-70). New York: New York Academy of Sciences.

Stein, M., OttenberG, M. D., \& Roulet, N. (1958). A study of the development of olfactory preferences. Archives of Neurological Psychiatry, 80, 264-266.

Sullivan, R. M., \& LEON, M. (1986). Early olfactory learning induces 
an enhanced olfactory bulb response in young rats. Developmental Brain Research, 27, 278-282.

Sullivan, R. M., \& LEON, M. (1987). One-trial olfactory learning enhances olfactory bulb responses to an appetitive conditioned odor in 7-day-old rats. Developmental Brain Research, 35, 307-311.

ToOBY, J., \& CoSMIDES, L. (1990). The past explains the present: Emotional adaptations and the structure of ancestral environments. Ethology \& Sociobiology, 11, 375-424.

Tulving, E. (1983). Elements of episodic memory. Oxford: Oxford University Press.

TURNER, B. H., MishKIN, M., \& KNAPP, M. (1980). Organization of amygdalopetal projections from modality-specific cortical association areas in the monkey. Journal of Comparative Neurology, 191, 515-543.

Turner, R., Le Bihan, D., Moonen, C. T. W., Despres, D., \& Frank, J. (1991). Echo-planar time course MRI of cat brain oxygenation changes. Magnetic Resonance in Medicine, 22, 156-166.
WALK, H. A., \& Johns, E. E. (1984). Interference and facilitation in short-term memory for odors. Perception \& Psychophysics, 36, 508-514.

WARRINGTON, E. K. (1982). The double dissociation of short- and long-term memory deficits. In L. S. Cermak (Ed.), Human memory and amnesia (pp. 61-76). Hillsdale, NJ: Erlbaum.

WHITE, T. (1992, April). A comparison of item and order processing in olfactory short-term memory. Paper presented at the 14th annual meeting of the Association for Chemoreception Sciences, Sarasota, FL.

Zatorre, R. J., Jones-Gotman, M., Evans, A. C., \& Meyer, E. (1992). Functional localization and lateralization of human olfactory cortex. Nature, 360, 339-340.

(Manuscript received June 9, 1995; revision accepted for publication March 18, 1996.) 